\title{
Effectiveness evaluation of a new surgical marker for anterior capsulorhexis
}

\author{
Avaliação da eficácia de um novo marcador \\ cirúrgico para capsulorrexe anterior
}

Marco Antônio Rey de Faria', Marcos Pereira de Ávila², Francisco Irochima Pinheiro ${ }^{3}$, Bruno Mendes de Faria ${ }^{4}$, Vinicius Nunes de Paiva Saraiva ${ }^{5}$, Joana Mendez Dantas de Miranda ${ }^{5}$, Germana Mariz Queiroga Veras Pinto ${ }^{5}$, Leonardo Ugulino de Araújo $\mathrm{Neto}^{5}$, Débora Cristiana Pereira Fernandes Santos ${ }^{6}$

\begin{abstract}
Purpose : To evaluate the effectiveness of a surgical device that intented to help in the preparation of the anterior capsulorhexis analyzing the design and shape, comparing with capsulorhexis made by free hand. Methods: Three ophthalmology residents(R3) at the HUOL and one surgeon in training, participate in this research as volunteers. Each surgeon perform 5 capsulorhexis in porcine eyes using the device, and five others by free hand as a control. All capsulorhexis were photographed having a ruler as reference to guide and calibrate a computer application for morphometric evaluation (Cambuí Labs, Natal, Brazil). All surgeons aimed to produce a circular continuous capsulorhexis of $5 \mathrm{~mm}$ diameter that represents 15,7 mm in perimeter and 19,652 $\mathrm{mm}^{2}$ in area. Each wet-lab capsulorhexis was evaluated in regard to these criteria: diameter (mean, maximum and minimum), perimeter, area, deviation from the ideal diameter and ideal shape. Results: Compare to control groups, capsulorhexis with the aid of the surgical device showed: 5,44mm $\pm 0,89 \mathrm{vs} 6,37 \mathrm{~mm} \pm 0,67$, for capsulorhexis diameter ( $p=0,001) ; 17,52 \mathrm{~mm} \pm 1,92 \mathrm{vs} 20,14 \mathrm{~mm} \pm 2,09$ for capsulorhexis perimeter $(<0.001) ; 24,73 \mathrm{~mm}^{2} \pm 1,92 \mathrm{vs} 32,62 \mathrm{~mm}^{2}$ $\pm 6,36$ for capsulorhexis area $(p<0,001)$. A tendency for better result with the aid of the surgical device was observed for deviation of an ideal diameter or ideal aspect were appreciated: $0,87 \mathrm{~mm} \pm 0,05 \mathrm{vs} 0,9 \pm 0,04$ for deviation of a curve $(p=0,06) ; 1,26 \mathrm{~mm} \pm 0,12 \mathrm{vs} 1,21 \mathrm{~mm}$ $\pm 0,7$ for the capsulorhexis aspect $(p=0,09)$. Conclusion: Capsulorhexis produced with the aid of the surgical device, significantly improved wet-lab capsulorhexis performance.
\end{abstract}

Keywords: Capsulorhexis/instrumentation; Cataract extraction/instrumentation; Lasers

\section{RESUMO}

Objetivo: Avaliar a eficácia de um novo marcador cirúrgico para ajudar na confecção da capsulorrexe anterior analisando o seu dimensionamento e formato, comparando com a capsulorrexe confeccionada manualmente de maneira livre. Métodos: Como experimento, 3 residentes (R3) de Oftalmologia do Hospital Universitário Onofre Lopes (HUOL) e 1 oftalmologista em treinamento, voluntários, realizaram (cada um) 10 capsulorrexes em olhos de porco enucleados. Em 5 olhos foi utilizado o marcador e em outros 5, não. Todos os olhos foram fotografados tendo ao lado uma régua para orientar e calibrar um aplicativo para a avaliação morfométrica do procedimento. O diâmetro alvo foi de $5 \mathrm{~mm}$, cujo perímetro correspondente é $15,7 \mathrm{~mm}$ e a área $19,652 \mathrm{~mm}^{2}$. Foram avaliados em cada procedimento: os diâmetros máximo, mínimo e médio, o perímetro, a área e o desvio em relação ao diâmetro e quanto ao aspecto ideal. Resultados: No grupo utilizando o marcador o diâmetro médio foi $5,44 \mathrm{~mm}( \pm 0,89)$ contra $6,37 \mathrm{~mm}( \pm 0,67)$ $(\mathrm{p}=0,001)$, no grupo no qual não se utilizou o marcador; quanto ao perímetro, $17,52 \mathrm{~mm}( \pm 1,92)$ no grupo utilizando o marcador contra $20,14 \mathrm{~mm}( \pm 2,09)(\mathrm{p}<0,001)$ sem o marcador e quanto a área, $24,73 \mathrm{~mm}^{2}( \pm 1,92)$ com o marcador, contra $32,62 \mathrm{~mm}^{2}( \pm 6,32)$ $(\mathrm{p}<0,001)$, sem o marcador. Em relação ao aspecto da capsulorrexe $1,26 \mathrm{~mm}( \pm 0,12)$, contra $1,21 \mathrm{~mm}( \pm 0,7)(\mathrm{p}=0,09)$ e em relação ao desvio de curvatura: $0,87( \pm 0,05)$, contra $0,9( \pm 0,04)$, $(\mathrm{p}=0,06)$ respectivamente. Conclusão: $O$ trabalho mostrou que o marcador avaliado é eficaz para auxiliar a confecção da capsulorrexe conduzindo a resultados melhores que o método a mão livre.

Descritores: Capsulorrexe / instrumentação; Extração de catarata / instrumentação; Lasers

\footnotetext{
${ }^{1}$ Health Sciences Center, Universidade Federal do Rio Grande do Norte, Penedo, Caicó - RN, Brazil.

${ }^{2}$ Faculdade de Medicina da Universidade Federal de Goiás (GO), Brasil;

${ }^{3}$ Universidade Federal do Rio Grande do Norte, Natal - RN, Brazil.

${ }^{4}$ Ophthalmology Service, Hospital Universitário Onofre Lopes, Natal, RN, Brazil.

${ }^{5}$ Ophthalmology Service at Hospital Universitário Onofre Lopes, Universidade Federal do Rio Grande do Norte, , Natal - RN, Brazil.

${ }^{6}$ Prontoclínica de Olhos, Natal, RN, Brazil.
}

Paper presented to the PPG in Health Sciences of the UFG to obtain the title of Master.

The authors declare no conflicts of interests.

Received for publication 22/09/2016 - Accepted for publication 01/12/2016. 


\section{INTRODUCTION}

$\mathbf{T}$ This work aims to evaluate the efficacy of a new surgical marker to help in the preparation of the anterior capsulorhexis by analyzing its size and shape, comparing it to the capsulorhexis made manually in a free way.

Cataract surgery with intraocular lens implant is the most performed surgical procedure in the world. In the United States of America, for example, more than 3 million surgeries are performed per year, and the benefits conferred on operated patients are remarkable. ${ }^{(1)}$ In Brazil it is estimated that there are about 550,000 new cases per year.(2) Despite the significant advances in the surgical technique in the last four decades, the main steps of surgery depend on the surgeon's manual ability.

One of the most important maneuvers of surgery, which is the making of continuous and circular capsulorhexis, is routinely carried out by the free hand, using a cystotome or an appropriate tweezer for that purpose, having as reference the pupillary margin and aiming a diameter that covers the entire edge of the intraocular lens evenly. ${ }^{(1)}$ Even in more experienced hands, an ideal capsulorhexis is not always achieved. The procedure is especially difficult in cases of small diameter pupils with shallow anterior chamber, zonular fragility, poor corneal transparency, in pediatric cataracts, mature cataracts, and capsular fibrosis. ${ }^{(3)}$

Adequately made capsulorhexis makes hydrodissection, hydrodelineation, nucleus maneuvers during phacoemulsification and cortical aspiration safer. The ideal capsulorhexis should be circular, well centered and cover $0.5 \mathrm{~mm}$ at the $360^{\circ}$ edge of the lens, ${ }^{(4)}$ which makes the intraocular lens completely within the capsular bag and at the effective position of the lens presumed by the formula for calculating the power of the lens, making postoperative refraction as predictable as possible. ${ }^{(3)}$

The performance of new intraocular lenses, especially socalled "premium lenses", which include multifocal, aspherical, toric and accommodative lenses, is directly related to regular capsulorhexis, of adequate size and centralization. ${ }^{(3,5)}$ But badmade capsulorhexis may lead to decentration of the lens and, especially in the case of multifocals, unwanted optical aberrations. ${ }^{(3)}$

For more than a decade, Femtosecond Laser has been developed and used for anterior segment surgeries, such as flap making for Lasik and recently for cataract surgery. One of the main arguments for its use is the making of a perfect capsulorhexis. ${ }^{(4)}$

In this sense, Kránitz et al., comparing the manual capsulorhexis with the one made with Femtosecond Laser, demonstrated that the latter is superior in shape, size and centralization. ${ }^{(4)}$ Nevertheless, the use of this new device presents an irmportant limiting factor in public health in our environment, which is its very high cost.

After an experience of more than 20 years teaching Residents to cataract surgery at the Ophthalmology Service of Universidade Federal do Rio Grande do Norte (UFRN), it was observed that for safety and reproducibility in the surgery there was the need to standardize the confection of capsulorhexis. This observation led the researchers to idealize and develop a specific instrument for this purpose. Then, they proposed to develop a low-cost marker capable of helping teach the correct preparation of capsulorhexis in its size and shape.

\section{Methods}

The marker developed for the accomplishment of the capsulorhexis is formed by two separated pieces made of surgical stainless steel, each piece in its distal end having a semicircular format with a diameter of $5.0 \mathrm{~mm}$, and thickness of $1.0 \mathrm{~mm}$. This semicircle is attached to the cable by a rod of the same thickness, also with $5.0 \mathrm{~mm}$ in length and inclined $5^{\circ}$ in relation to the semicircles and $15^{\circ}$ in relation to its cable. The semicircle marking the capsule was milled on its face towards the crystalline to retain more dye and thus impregnate the anterior capsule of the crystalline (Figure 1).
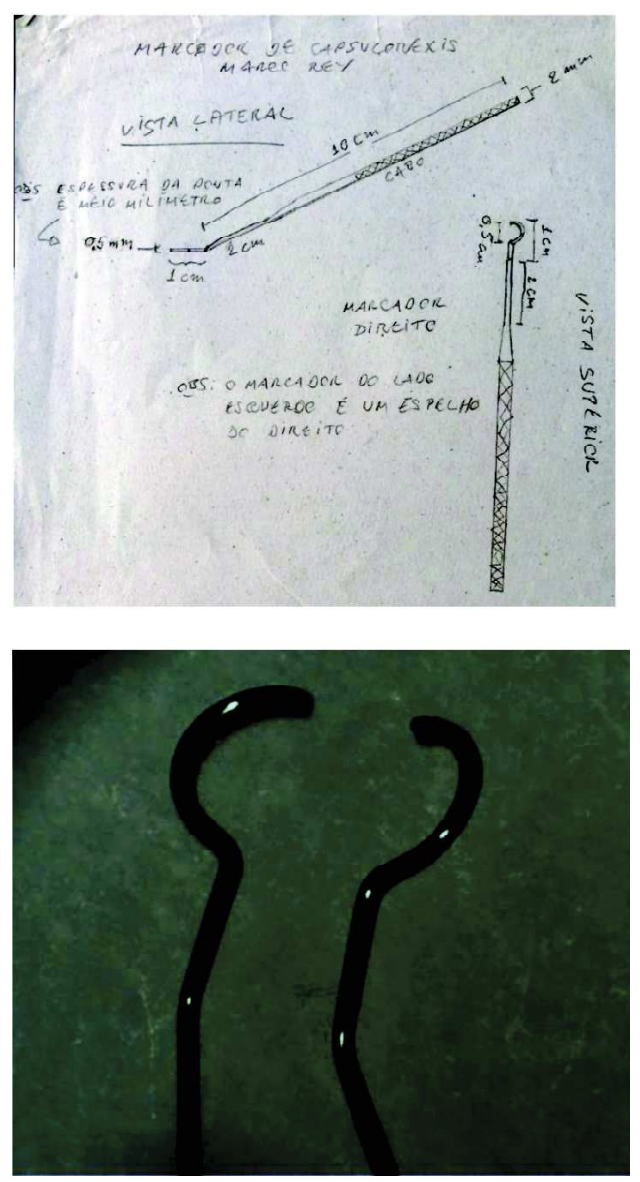

Figure 1: On the left we can see the first project of the marker made by the researcher. On the right, the marker already made in stainless steel (photo of the author).

This research had the participation of three volunteers, training physicians of the third year of the Ophthalmology Residency at Hospital Universitário Onofre Lopes da UFRN, who already have basic skills in the execution of cataract surgery, and another volunteer ophthalmologist undergoing specialization in cataract surgery, which were selected to perform the experimental procedures.

Each of the 4 participants performed 10 anterior capsulorhexis on enucleated pig eyes, for a total of 40 eyes. These eyes were used in the experiment less than 48 hours after enucleation. Of the 10 capsulorhexis performed by each of the 
volunteer physicians, 5 were made "freehand" as usual, and 5 using the new marker developed for that purpose. The 5 "freehand" procedures performed were made using a tweezers for capsulorhexis model Jones-Inamura millimeter, to give guidance as to the size of the same to the surgeon. The same tweezer was used for the capsulorhexis made with the use of the marker.

Although postmortem human eyes are ideal for any experiment, it is still unfeasible to get them in enough amount, with the pig eye being the closest alternative to enable eye surgeon training practically all over the world. ${ }^{(6,7)}$

Prior to capsulorhexis, regardless of technique (with or without marker), the anterior capsule was stained with $0.3 \mathrm{ml}$ of trypan blue $10 \%$. An air bubble was then injected into the anterior chamber, and then $0.05 \mathrm{ml}$ of a solution formed by 0.3 $\mathrm{ml}$ of formaldehyde $30 \%$ with $0.7 \mathrm{ml}$ of methyl cellulose $2 \%$ was gently injected over the anterior capsule with a 25 -gauge cannula introduced through the limbus to harden the anterior capsule of the pig's eyes to become more similar to the human eyes $^{(8)}$. After 1 minute, the anterior chamber was filled with methylcellulose $2 \%$.

When the new capsulorhexis marker was used, it was previously stained with methylene blue on its face towards the crystalline, and then introduced into the anterior chamber, one semicircle at a time. With the marker in the anterior chamber, a slight pressure was applied on the anterior capsule of the crystalline in order to mark it, then the capsulorhexis was operated with tweezers.

In the eyes where the marker was not used, after the same hardening process, the anterior capsule of the crystalline was stained with trypan blue $0.1 \%$, and the anterior chamber was filled with methylcellulose $2 \%$, and then capsulorhexis was made freehand. The target diameter of the capsulorhexis was 5 $\mathrm{mm}$ for all cases.

The order of physicians to perform the procedure was established at random, as well as the first technique to be done (with or without marker) in order to randomize the experiment. After the capsulorhexis was completed, the capsules were photographed using the surgical microscope Verion ${ }^{\mathrm{TM}}$ Image Guided System (Alcon Fort Worth-USA), with a millimeter ruler placed next to the cornea to guide and calibrate the application that analyzed the dimensions of capsulorhexis. This morphometric evaluation application was specially developed for the analysis of this experiment by Cambuí Labs. (Natal, Brazil) because there was no software in the market that would meet our needs.

The capsule analysis application was created based on the integrated development environment and the free software from Apple Inc. called Xcode. The XCode used in the project was the version available at the time (6.2), having tools to create applications in a simple and powerful way. This programming environment can be obtained directly from the Apple developers website (http://developer.apple.com/) at no cost to the user and free to use.

This system captures the image selected and is calibrated for the analysis of the dimensions by adjusting it to the millimeter ruler photographed beside the eye studied.

It is centered on the capsular tissue removed by the capsulorhexis. The contour of the capsulorhexis is then manually marked, and then the system automatically analyzes the desired parameters, as shown in figure 2.
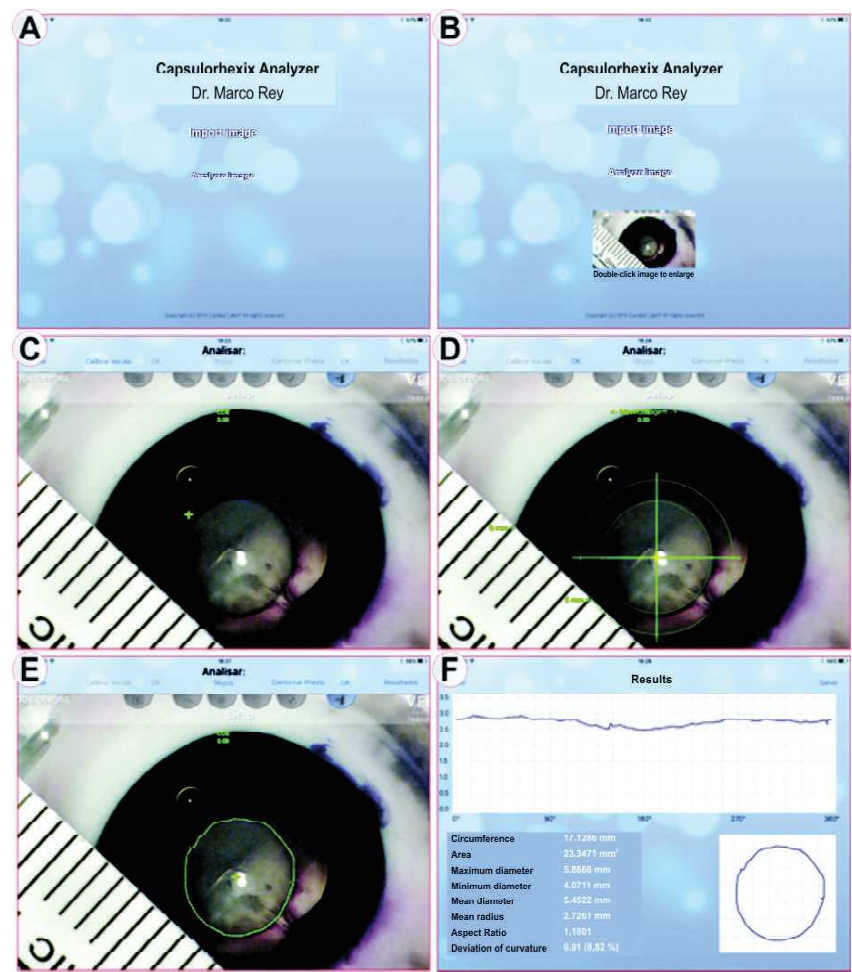

Figure 2: A - Application start screen. B - Capture of the image chosen. $\mathbf{C}$ and $\mathbf{D}$ - Centralization and calibration of the application by the ruler photographed during the experiment. $\mathbf{E}$ - Manual contour of capsulorhexis. F - Image analysis. (Photos of the author).

The morphometric system used allowed to evaluate the following parameters of the area corresponding to the capsular tissue removed by capsulorhexis: maximum diameter; minimum diameter, mean diameter; mean ray; aspect relation to a perfect circle; and deviation from the curvature. These data allowed the exact evaluation of the capsular tissue removed during the surgical maneuver, and was used in the comparison between capsulorhexis techniques in eyes treated by the same surgeon and in the interpersonal comparison of the four surgeons.

The indicator of the standard to be reached was considered when the capsulorhexis dimensions were within a range of more or less $1.0 \mathrm{~mm}$ from the target of $5.0 \mathrm{~mm}$ diameter in all meridians measured. Regarding the statistical analysis, it was made with the program Stata 11 (Stata Corp. TX, USA). Multiple regression was used to test the mean difference between the two groups, being adjusted for the operator's category.

Methylene blue is the dye used in the pens for surgical marking. In order to reduce the cost of this experiment, we used pens already used in other surgeries to mark the astigmatic axis. As they would be discarded, they were used for dyeing the marker, which due to being enucleated pig eyes are not danger for toxicity. Pens with trypan blue can be ordered for use in human eyes, which is the best indication.

This research project was previously submitted to the approval of the Research Ethics Committee of UFRN in accordance with Law 11.794/2008 of the Ministry of Health. 


\section{RESULTS}

With respect to the circumference, we know that the perimeter of a circle of $5 \mathrm{~mm}$ is $15.7 \mathrm{~mm}$, this being the target circumference for the experiment. In the group SEM (without marker) the average was $20.14 \mathrm{~mm}( \pm 2.09)$, versus $17.52 \mathrm{~mm}( \pm 1.92)$ in the group COM (with marker), which leads to a difference in the group that used the marker of $-2.62 \mathrm{~mm}$ in relation to the group SEM, this difference being statistically significant with $\mathrm{p}<0.001$.

Regarding the area, whose measure corresponding to a $5.0 \mathrm{~mm}$ diameter circle is $19.652 \mathrm{~mm} 2$, the group SEM obtained an average of $32.62 \mathrm{~mm} 2( \pm 6.36)$, whereas the group COM had an average of $24.73 \mathrm{Mm} 2( \pm 1.92)$. Therefore, the group that used the marker reduced $7.881 \mathrm{~mm} 2$, which is statistically significant with a $\mathrm{p}<0.001$.

In the evaluation of the maximum, minimum and mean diameters there was also a significant difference closest to the ideal $(5.0 \mathrm{~mm})$ in the group that used the marker, as shown in the spreadsheet for calculating differences $(\mathrm{p}=0.001)$.
At the maximum diameter, the group SEM had a mean of $7.01 \mathrm{~mm}( \pm 0.73)$ versus $6.20 \mathrm{~mm}( \pm 0.76)$ of the group COM. At the minimum diameter, the group SEM had an average of $5.83 \mathrm{~mm}$ $( \pm 0.68)$ versus $4.93 \mathrm{~mm}( \pm 0.59)$ of the group COM, and in the mean diameter evaluation the group SEM had $6.37 \mathrm{~mm}( \pm 0.67)$, whereas the group COM had $5.44 \mathrm{~mm}( \pm 0.89)$.

In the deviation for the ideal curvature, the group SEM had $0.9 \mathrm{~mm}( \pm 0.04)$ of deviation and the group COM had $0.87 \mathrm{~mm}( \pm$ 0.05 ) deviation, a difference that, although smaller, with a $\mathrm{p}=0,06$, is not statistically significant, as well as the average of the capsulorhexis aspect ratio, which was $1.21( \pm 0.07)$ in the group SEM versus 1.26 $( \pm 0.12)$ in the group COM, whose $p$ is equal to 0.09 .

These measures show that the group in which the marker was used was much closer to the target, which was a morphometrically uniform capsulorhexis with $5 \mathrm{~mm}$ in diameter. Table 1 below shows the results of the statistical analysis of the work.

Figures 3 to 7 show the comparative graphs of the groups with and without the use of the marker for capsulorhexis orientation.

Table 1

Results of the statistical analysis

\begin{tabular}{|c|c|c|c|c|c|c|c|c|c|c|c|c|}
\hline \multirow[b]{3}{*}{ Circunference $(\mathrm{mm})$} & \multicolumn{4}{|c|}{ SEM } & \multicolumn{4}{|c|}{ COM } & \multicolumn{4}{|c|}{ Diference } \\
\hline & \multirow{2}{*}{$\frac{\mathbf{m}}{20.14}$} & \multirow{2}{*}{$\frac{\text { SD }}{2.09}$} & \multicolumn{2}{|c|}{ CI95\% } & \multirow{2}{*}{$\frac{\mathbf{m}}{17.52}$} & \multirow{2}{*}{$\frac{\text { SD }}{1.92}$} & \multicolumn{2}{|c|}{ CI95\% } & \multirow{2}{*}{$\frac{\mathbf{m}}{-2.614}$} & \multicolumn{2}{|c|}{ CI95\% } & \multirow{2}{*}{$\begin{array}{r}\text { P-value } \\
<0.001\end{array}$} \\
\hline & & & 19.16 & 21.12 & & & 16.63 & 18.43 & & -3.834 & -1.394 & \\
\hline Deviation to $15.7 \mathrm{~mm}$ & 4.44 & 2.09 & 3.46 & 5.42 & 1.83 & 1.92 & 0.93 & 2.73 & & & & \\
\hline Área (mm) & 32.62 & 6.36 & 29,64 & 35.60 & 24.73 & 5.53 & 22.14 & 27.32 & -7.891 & -11.533 & -4.248 & $<0.001$ \\
\hline Deviation to $19.625 \mathrm{~mm}$ & 12.99 & 6.36 & 10.02 & 15.97 & 5.10 & 5.53 & 2.51 & 7.,69 & & & & \\
\hline Maximum diameter (mm) & 7.01 & 0.73 & 6.67 & 7.35 & 6.20 & 0.76 & 5.85 & 6.56 & $-0,807$ & -1.248 & -0.365 & 0.001 \\
\hline Minimum diameter (mm) & 5.83 & 0.68 & 5.51 & 6.15 & 4.93 & 0.59 & 4.66 & 5.21 & $-0,899$ & -1.289 & -0.508 & $<0.001$ \\
\hline Mean diameter (mm) & 6.37 & 0.67 & 6.06 & 6.69 & 5.44 & 0.89 & 5.03 & 5.86 & -0.929 & -1.432 & -0.424 & 0.001 \\
\hline Desvio para $5 \mathrm{~mm}$ & 1.3 & 0.67 & 1.06 & 1.69 & 0.44 & 0.89 & 0.03 & 0.86 & & & & \\
\hline Aspect Ratio & 1.21 & 0.07 & 1.17 & 1.24 & 1.26 & 0.12 & 1.21 & 1.32 & 0.056 & -0.009 & 0.122 & 0.091 \\
\hline Deviation of curvature (\%) & 0.90 & 0.04 & 0.88 & 0.91 & 0.87 & 0.05 & 0.84 & 0.89 & -0.027 & -0.055 & 0.001 & 0.060 \\
\hline
\end{tabular}

m: Mean; SD: Standard deviation, CI: Confidence Interval

\section{Mean circunference of capsulorhesis according to the method used}

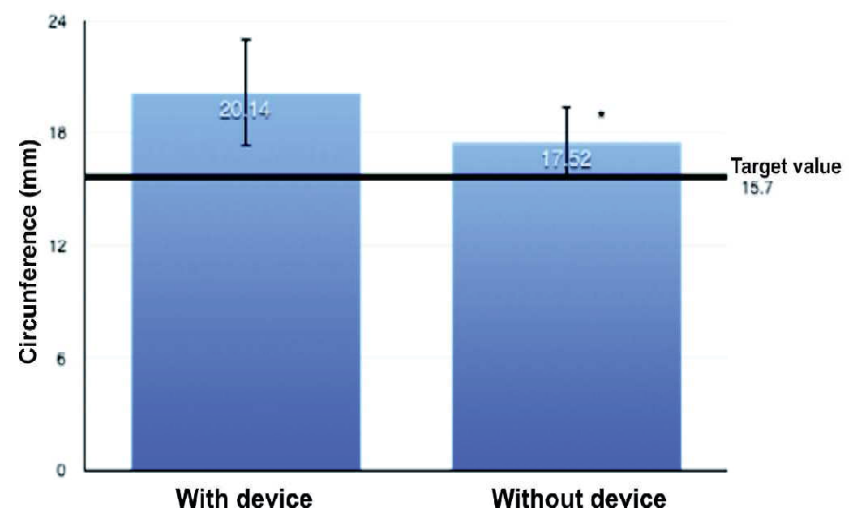

Figure 3: Comparison between the mean capsulorhexis circumferences produced without and with the new marker under study. The circumference produced when using the new marker is significantly closer to the target value of $15.7 \mathrm{~mm}(* \mathrm{p}<0.001$, multiple regression testing the difference of means between the two groups by adjusting for operator category).

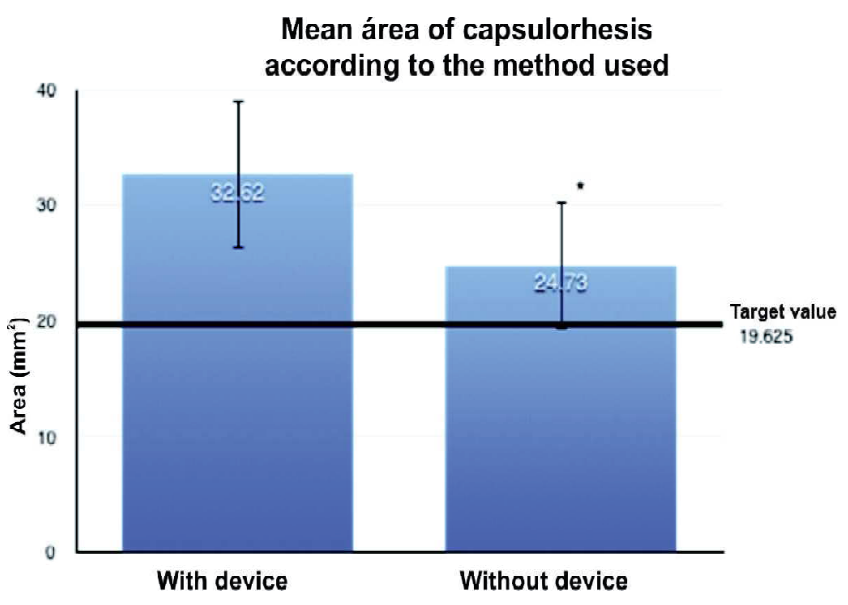

Figure 4: Comparison between the mean capsulorhexis areas produced without and with the new marker under study. The mean area produced when using the new marker is significantly closer to the target value of $19.625 \mathrm{~mm}(* \mathrm{p}<0.001$, multiple regression testing the difference of means between the two groups by adjusting for operator category). 
Mean of maximum, mean and minimum diameters
of capsulorhesis according to the method used

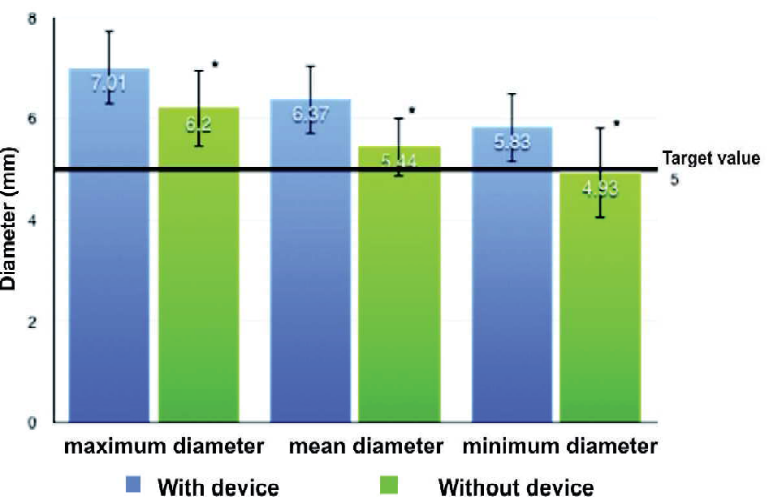

Figure 5: Comparison between the means of maximum, mean and minimum diameters of capsulorhexis produced without and with the new marker under study. The diameters produced when using the new marker is significantly closer to the target value of $5 \mathrm{~mm}(* \mathrm{p}<0.001$, multiple regression testing the difference of means between the two groups by adjusting for operator category).

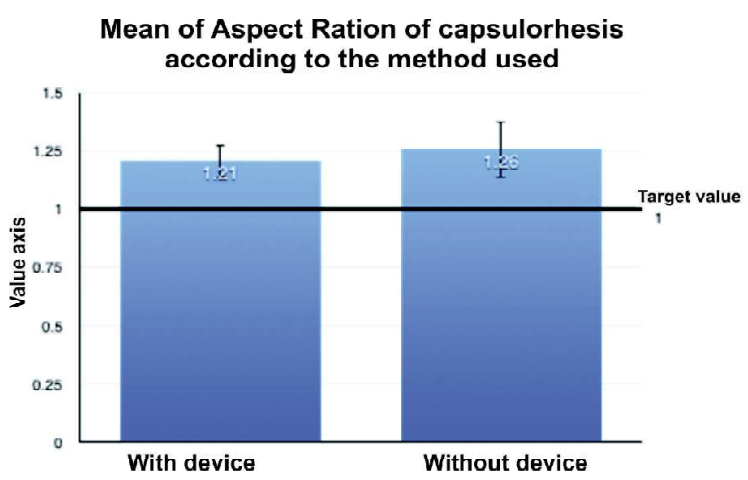

Figure 6: Comparison between the mean Aspect Ratio of capsulorhexis produced without and with the new marker under study. No significant difference was observed between the two methods ( $\mathrm{p}=0.09$, multiple regression testing the mean difference between the two groups by adjusting for operator category).

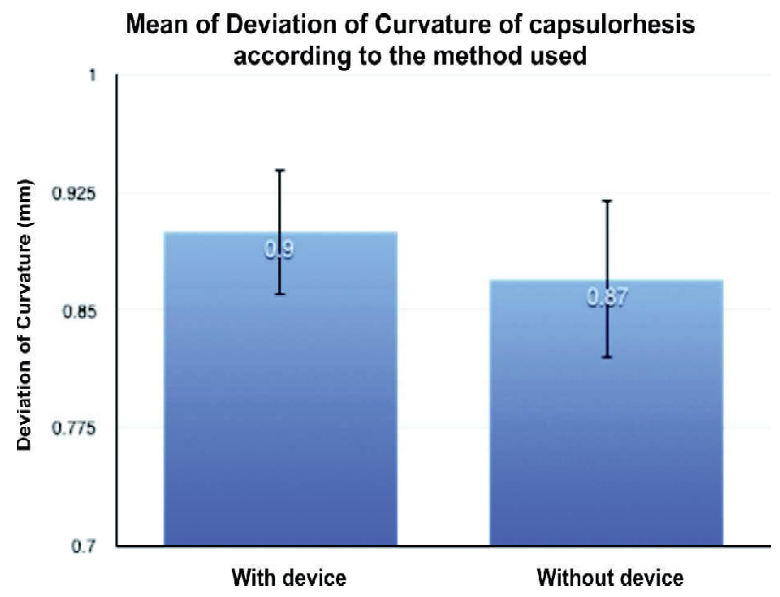

Figure 7: Comparison between the mean deviation of curvature of capsulorhexis produced without and with the new marker under study. Although there was no significant difference, there was a tendency for a smaller deviation of curvature when the new marker was used ( $p$ $=0.06$, multiple regression testing the difference of the means between the two groups by adjusting for operator category).

\section{Discussion}

A continuous curvilinear capsulorhexis is essential for the success of a phacoemulsification with safe intraocular implant lens because it allows maneuvers such as hydrodissection, adequate cortical cleaning, intraocular lens centration, as well as inhibits posterior capsule opacification $(\mathrm{PCO}) \cdot{ }^{(9)}$

An ideal capsulorhexis that prevents PCO should be well centered and with enough diameter to cover precisely the margin of the intraocular lens. Studies have shown that coverage of the lens edge is an important protective factor in PCO development rather than the design of the lens edge. ${ }^{(9,10)}$

The size of the capsulorhexis is also related to the better positioning of the lens in a postoperative evolution. If it is too small or too large, it may cause the lens to be offset or inclined. ${ }^{(6)}$

The present study showed that capsulorhexis made with the aid of the new marker presented reproduce diameters, areas and circumferences significantly closer to the target parameters than those produced by the free hand. It should be emphasized that this differentiation between the techniques was obtained even in the hands of trained and theoretically less experienced cataract surgeons. This data corroborates the greater ease of the surgical marker tested in the execution of this critical stage in the cataract surgery.

The centering and deviations from a perfect circle tended to present better responses with the help of the new marker than those produced by the free hand, although they were not statistically significant. In this sense, probably an increase in the number of experiments could provide better discrimination.

The marker tested provides a concrete reference for the size and shape of the capsulorhexis and it is probable that a system that ensures its better centration can further enhance the characteristics of the capsulorhexis produced. In the experiment, the centration depended on the subjective observation of the surgeon through the microscope, without the aid of a system such as Verion (Alcon Laboratories, Inc., Fort Worth,TX) which was subsequently used to evaluate the resulting capsulorhexis. As the objective of the study was to seek a less costly option than a femtosecond laser in the construction of capsulorhexis, it could not rely on a sophisticated intra-operative positioning system. An improvement in the marker used still lacks better development also seeking a better centration of the capsulorhexis.

Other studies show a better accuracy in the size and shape of the capsulorhexis performed with the femtosecond laser when compared to the manual technique ${ }^{(1,3,4)}$, as should also occur if a digital marker system is used. However, because they are extremely expensive technologies, the development of devices such as the one tested in the present study has great socioeconomic importance for the national reality, since it brings quality in cataract patient care, as well as economic viability, increasing the efficiency of our public health system.

Cataract surgery is the most commonly performed surgery in the world, and according to the World Health Organization (WHO), cataract remains the leading cause of blindness worldwide..$^{(11,12)}$ It is also one of the major national health problems. ${ }^{(13)}$ Due to this demand and the difficulty of funding by SUS, it is necessary to look for options that are more cos-effective as the technique proposed by the present study.

Another advantage to the system tested in this study is in the area of teaching the surgical technique that can bring safety 
and quality in the surgical results of our residents and physicians in specific training.

One of the problems faced when teaching surgical procedures is to find models that simulate the clinical conditions that the student will face in real life. The ideal model would obviously be to use human cadaver eyes, ${ }^{(6,7)}$ but having them available in enough numbers for training is practically impossible in our environment.

Pig eyes are the most similar in size to human eyes; however, there are some very different characteristics, and the main one is the anterior capsule of the crystalline with much more tension and elasticity, which makes it very difficult to teach

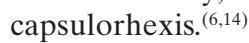

According to Sugiura et al., the formalin fixation of the crystalline capsule of the pig's eye makes them more similar to those of human eyes. Their technique is to inject formaldehyde behind the iris, inside the lens, underneath the anterior capsule with a 27 gauge needle, waiting 10 minutes to have a cataract with capsule and nucleus similar to the human's ${ }^{(7)}$.This technique, however, presents two difficulties, namely: it demands time between one procedure and the other, and requires the ability to perform it without damaging the anterior capsule. In this sense, Chigusa et al. ${ }^{6}$ suggest an easier and more reproducible technique (already described in the Methods), and for this reason used in the present experimentation.

\section{Conclusion}

The present study showed that the new surgical marker is effective to help the preparation of capsulorhexis, leading to better morphometric results than the freehand method, and very close to the desired target objective both in its dimensioning and its format, besides being able to serve as model for teaching ophthalmologists in trainings for cataract surgery.

\section{REFERENCES}

1. Friedman NJ, Palanker DV, Shuele G, Andersen D, Marcellino G, Seibel BS. Femtosecond laser capsulotomy. J. Cataract Refract Surg. 20111; 37(7): 1189-1198.

2. Oliveira LL, Avila P, Isaac DL, Rocha MN, Mendonça LS. Análise de Prevalência e Epidemiologia da Catarata na População Atendida no Centro de Referência em Oftalmologia da Universidade Federal de Goiás. SBPC. [citado 2016 jun. 18]. Disponível em: http://www.sbpcnet.org.br/livro/63ra/conpeex/ pivic/trabalhos/LAIS_LEA.PDF

3. Gerd UA, Reddy KP, Ritter R, Holzer MP, Rabsilber TM. Comparison of the maximum applicable stretch force after femtosecond laser-assisted and manual anterior capsulotomy. J Cataract Refract Surg 2013; 39:105-109.

4. Kránitz K, et al. Femtosecond laser capsulotomy and manual continuos curvilinear capsulorhexis parameters and their effects on intraocular centration. J. Cataract Refract Surg. 2011 aug; $27(8) ; 558-563$.
5. Gimbel MD. The History of the Capsulorhexis Techinique. Cataract Refract Surg Today. 2007; 39-41. Available from: http:// crstoday.com/articles/2007-oct/crst1007_08-php/

6. Hashimoto C, Kurosaka D, Uetsuki Y. Teaching continuous curvilinear capsulorhexis using a post-mortem pig eye with simulated cataract. J Cataract Refract Surg. 2001 jun; 27:814-816

7. Sugiura et al. Creating cataract in a pig eye. J. Cataract Refract Surg 1999; 25(5):615-621.

8. Esporcatte LPG, Bisol RAR, Dias FR. Anatomia e fisiologia do cristalino. In: Faria MAR, Nosé W, Mello AA. Catarata. 1. ed. Rio de Janeiro: Cultura Médica; 2015. p.9-14.

9. Powers MA, Kahook MY. New device for creating a continuous curvilinear capsulorhexis Matthew A. J Cataract Refract Surg, 2014 maio; 40(5):822-830.

10. Mastropasqua L, Toto L, Calienno R, Mattei PA, Mastropasqua A, Vecchiano L, Di Iorio D. Scanning electron microscopy evaluation of capsulorhexis in femtosecond laser-assisted cataract surgery. J Cataract Refract Surg, 2013; 39(10);1581-1586.

11. Kara-Júnior N, Dellapi Jr R, Espínola RF. Dificuldades de acesso ao tratamento de pacientes com indicação de cirurgia de catarata nos Sistemas de Saúde Público e Privado. Arq. Bras. Oftalmol. São Paulo, 2011 set-out; 74(5).323-5.

12. Oliveira F, Silva LM, Muccioli C, Soriano ES, Freitas LL, Belfort $\mathrm{J}$ R. Qualidade de vida de pacientes pseudofácicos submetidos à cirurgia de catarata com implante de lente intra-ocular acomodativa. Arq. Bras. Oftalmol. 2004; 67(3):469-74

13. Fontes PC. Olhares sobre o Brasil. Bloco Catarata; 2012. p.39-41.

14. Hendersen B, Grimes KJ, Fintelmann RE, Oetting TA. Stepwise approach to establishing an ophthalmology wet laboratory. J

\section{Corresponding author}

Marco Antônio Rey de Faria

R. Dr. Ewerton Dantas Cortez, no 1504 - Apto. 1501 - Tirol

Natal (RN), Brasil

Email: marco.rey@uol.com.br

\section{ERRATA}

In the scientific article "Evaluation of the efficacy of a new surgical marker for anterior capsulorrexis", with the number of DOI 10.5935 / 0034-7280.20170003, published in Revista Brasileira de Oftalmologia, volume 76, number 1, January-February 2017; p. 11-6, on page 11: for a misunderstanding was not included the name as the author of Marcos Pereira de Ávila, professor of ophthalmology of the Faculty of the Federal University of Goiás is the information that the work was presented to PPG in Health Sciences of UFG to obtain the title of Master. 